\title{
Effect of Lifestyle Modification on BMI, Skin Fold Thickness and Lipid Profile in Obese and Overweight Children Aged 7-11 Years
}

\author{
Padmakumar Padmanabhan ${ }^{1}$, Mohankumar M. K. ${ }^{2}$ \\ 1Department of Paediatrics, IMCH Medical College, Calicut, Kerala, India. \\ ${ }^{2}$ Department of Paediatrics, IMCH Medical College, Calicut, Kerala, India.
}

\section{ABSTRACT}

\section{BACKGROUND}

Childhood obesity and overweight are global problems that are on the rise. Overweight and obesity are indications of an increasingly indolent society. This imbalance in calories intake and expenditure causes overweight. Childhood obesity leads to hypertension, type 2 diabetic mellitus, dyslipidaemia, steatohepatitis, obstructive sleep apnoea, orthopaedic and psychosocial problems. Lifestyle modification reduces the risk of overweight and obesity.

\section{METHODS}

This is an interventional study with a duration of 1 year conducted among children in the age group 7-11 years at endocrinology clinic, IMCH, Calicut, with BMI $>85 \%$. Overweight and obese children and parents were educated together about the complications of overweight. These children were advised lifestyle modifications like physical exercise, increased sleeping hours, reduced TV watching, increased vegetable intake decreased fat intake. BMI and skin fold thickness were measured every 3 months; lipid profile and FBS every 6 months.

\section{RESULTS}

After lifestyle modification, out of 29 overweight children, the BMI of 20 children reduced. Similarly, out of 35 obese children, 19 children BMI reduced. Triceps skin fold thickness is an important tool to assess overweight and obesity. In lipid profile, cholesterol, LDL cholesterol and triglyceride show significant reduction. There is not much reduction in fasting blood sugar.

\section{CONCLUSIONS}

Major risk factors identified in childhood obesity are lack of physical exercise, excessive TV viewing, inadequate sleep and wrong selection of food items i.e. eating food containing excess of carbohydrates, lack of adequate fruits and vegetables. Lifestyle modification is effective in reducing body mass index in childhood obesity. Significant reduction is seen in overweight boys compared to girls. Lifestyle modification is useful in bringing down total cholesterol, triglyceride, LDL cholesterol and elevation of HDL cholesterol. There is no significant reduction in fasting blood sugar.

\section{KEY WORDS}

Overweight, Obesity, Lifestyle Modification
Corresponding Author:

Dr. Mohankumar Muthuswamy Krishnamma, Department of Paediatrics,

Government Medical College,

Thrissur, Kerala, India.

E-mail: kumarmohan1317@gmail.com

DOI: $10.14260 /$ jemds/2019/778

Financial or Other Competing Interests: None.

How to Cite This Article:

Padmanabhan, P, Mohankumar MK. Effect of lifestyle modification on BMI, skin fold thickness and lipid profile in obese and overweight children aged 7-11 years. J. Evolution Med. Dent. Sci. 2019;8(48):36043608, DOI: 10.14260/jemds/2019/778

Submission 26-07-2019,

Peer Review 14-11-2019,

Acceptance 20-11-2019,

Published 02-12-2019. 


\section{BACKGROUND}

Childhood obesity and overweight are global problems that are on the rise. ${ }^{1}$ Although obesity was initially most prevalent in developed countries, it is now seen to co-exist with under nutrition in developing countries. In India obesity has reached epidemic proportions in the $21^{\text {st }}$ century, with morbidity affecting $5 \%$ of our population. Overweight and obesity are indications of an increasingly indolent society. ${ }^{2}$ This imbalance in calories intake and expenditure causes overweight.

\section{Sequelae of Childhood Obesity}

Hypertension, Type 2 diabetic mellitus, dyslipidaemia, steato hepatitis, obstructive sleep apnoea, orthopaedic and psychosocial problems $3,4,5$ are the common sequelae of overweight. The purpose of the study is to evaluate the effect of lifestyle modifications in overweight by assessing BMI, skin fold thickness, and lipid profile. Lifestyle modifications such as soft drink reduction ${ }^{6}$, low fat diet, 7100 gm vegetables per day, ${ }^{8}$ restricted TV watching, ${ }^{9}$ extra hour sleep ${ }^{10}$ and physical activity ${ }^{11}$ are advised to these children and effect is assessed by skin fold thickness and BMI every 3 months for 1 year and lipid profile at 6 months interval.

\section{Immediate and Social Sequelae}

The metabolic consequences of obesity, development of hepatitis, and gallstones. Eating disorders such as anorexia or bulimia. Skin infections due to moisture from sweat being trapped in skin folds. Moreover, obesity in childhood can also result in serious psychological difficulties. They are more likely to be teased and bullied, and more likely, childhood obesity to challenge worldwide public health. Substantial consequences to physical and mental health both short and long term must be anticipated. Many health consequences to paediatric obesity are as follows: Metabolic consequences of obesity develop hepatis and gallstones, increased intracranial pressure and sleep apnoea syndrome, Orthopaedic sequelae include presence of unfused growth plate and softer cartilaginous bones of children, causes bone abnormalities in obese children, permanent damage to femoral head may occur when dislocation occurs in femoral growth plate. The incidence of slipped capital epiphysis is approximately 3.4 per 100,000 children. Severe infantile blounts disease appears associated with obesity in children, approximately, 80\% Neurological sequelae include idiopathic increased intracranial hypertension (pseudotumor cerebri) usually present with diplopia, blurred vision, headache, vomiting. Increased intra-abdominal pressure due to obesity will increase in intrapleural pressure and cardiac filling pressure which in turn results in increased resistance to venous return from the brain and causes increased intra cranial pressure. Pulmonary complications include asthma, and sleep apnoea. Pickwickian syndrome refer to severe obesity associated with hypoventilation, somnolence, polycythaemia and right ventricular hypertrophy and failure. Gastroenterological sequelae include gall stone formation. Increased rates of lipolysis in obese individuals and insulin resistance, combine leading to liver stenosis, steato hepatitis, liver fibrosis and cirrhosis. Degree of obesity, duration, and male gender are associated with progression of fatty liver to fibrosis. Endocrine sequelae associated with obesity are significant insulin resistance and hyper androgenemia, insulin resistance is associated with higher levels of total cholesterol low density lipoprotein (LDL) cholesterol, and triglycerides. Development of severe insulin resistance associated with the increased prevalence of non-insulin depend diabetes mellitus (NIDDM) in obese children. Menstrual abnormalities in obese children are also common. Late or absent menstruation is also associated with obesity. Polycystic ovarian syndrome (oligomenorrhea or amenorrhea associated with obesity insulin resistance hirsutism, acne and acanthosis nigricans constitutes) this syndrome. Intermediate consequences risk of heart disease and atherosclerosis is elevated in males and females. Risk of colonic cancer and gout is elevated for males. Childhood obesity increases left ventricular mass irrespective of blood pressure status. Long term consequences include adult morbidity and mortality.

We wanted to evaluate the effect of lifestyle modification on BMI, skin fold thickness and lipid profile in exogenous overweight/ obese children aged 7-11 yrs.

\section{METHODS}

This is an interventional study conducted between July 2010 and July 2011 conducted among 64 children in the age group of 7-11 years attending Endocrinology Clinic, IMCH, Calicut with BMI percentile $>85$. The study was approved by the Institutional Ethics Committee and the Informed consent was obtained from study participants. Children having endocrine disorders or obesity syndromes and children on chronic medications like steroid therapy were excluded from the study.

\section{Operational Definitions}

Obese- Defined as body mass index $\geq 95^{\text {th }}$ centile for age and gender specific BMI. Overweight- Defined as body mass index between $85^{\text {th }}$ and $94^{\text {th }}$ centile for age and gender specific BMI.

\section{Methods of Implementation}

Overweight children and parents are educated together about the complications of childhood overweight by direct verbal communications. The child with BMI 85-94 percentile is considered as overweight and BMI with $\geq 95$ is considered as obese. They are advised to follow the instructions in lifestyle modifications mentioned below strictly and its close monitoring and follow up were done.

\section{Anthropometry}

- Weight: Weight is measured using electronic scale having $0.01 \mathrm{Kg}$ accuracy and is compared before and on each visit after the lifestyle modification with the pre lifestyle modification values.

- Height: Height is measured to nearest $0.1 \mathrm{~cm}$ with stadiometer with subjects lightly dressed, without shoes and is compared before and on each visit after the lifestyle modification with the pre lifestyle modification values.

\section{Body Mass Index}

BMI is calculated as weight in kilograms divided by height in meter square. BMI is calculated at first visit, after 3 months, 6 months, 9 months and 1 year and is compared before and on each visit after the lifestyle modification with the pre lifestyle 
modification values. Values are categorized as overweight and obese with gender distribution.

\section{Skin Fold Thickness}

Harpenden skin fold caliper which measures skinfold thickness in $\mathrm{mm}$ in the following five sites.12- triceps, biceps, mid-thigh, abdomen and calf. The skin fold thickness is measured in mm using Harpenden skin fold caliper before and after lifestyle modification on each visit. The values noted as either increase, decrease or static with the initial values (before lifestyle modification). The values are categorized as overweight and obese with gender distribution. Lipid profile was measured before lifestyle modification and it was compared with standard values on each follow up visit.

\section{Fasting Blood Sugar}

Normal $(<100)$, above euglycemic (100-125), hyperglycaemic $(>125)$. Fasting blood sugar is also compared as above.

\section{Statistical Analysis}

Quantitative variables were summarised as mean and standard deviation (SD) while qualitative variables were summarised as frequencies and percentages.

\section{RESULTS}

\section{Gender Distribution}

Of the 64 children, 34 (53\%) were males and $30(47 \%)$ were females.

\section{Risk Factors for Obesity}

\section{Physical Exercise}

In this study, $70 \%$ were with no exercise, $11 \%$ with less than 1 hour and 19\% were with $>1$-hour exercise.

\section{Duration of Exercise}

Regular exercise is an important factor that decreases obesity. In present study, majority (71\%) of children were not taking any regular exercise (Table 2 ).

\section{TV Viewing Time}

There is a positive correlation between TV viewing time and overweight / obese. In present study majority (52\%) of children are viewing TV of more than two hour per day, $37 \%$ $0-2$ hours and no TV viewing time $11 \%$.

Duration of Sleeping Hours

In this study majority of children $(87.5 \%)$ were not sleeping adequately, $11 \%$ normal sleep and $2 \%$ more than normal sleep.

\section{Fat Intake}

In this study $80 \%$ took normal fat intake and $20 \%$ high fat intake.

\section{Number of Feeds per Day}

Majority (80\%) of overweight/obese children are taking normal fatty diet. Even though excess fat intake is not seen in any of obese children, they are getting excess calorie from increased intake of food containing excess carbohydrate. In this study 36 persons (56\%) takes 4 meal per day and 28 persons (44\%) takes 3 meals per day.
Vegetables/Fruits Intake

Only a negligible number of children (9.4\%) are taking enough vegetables.

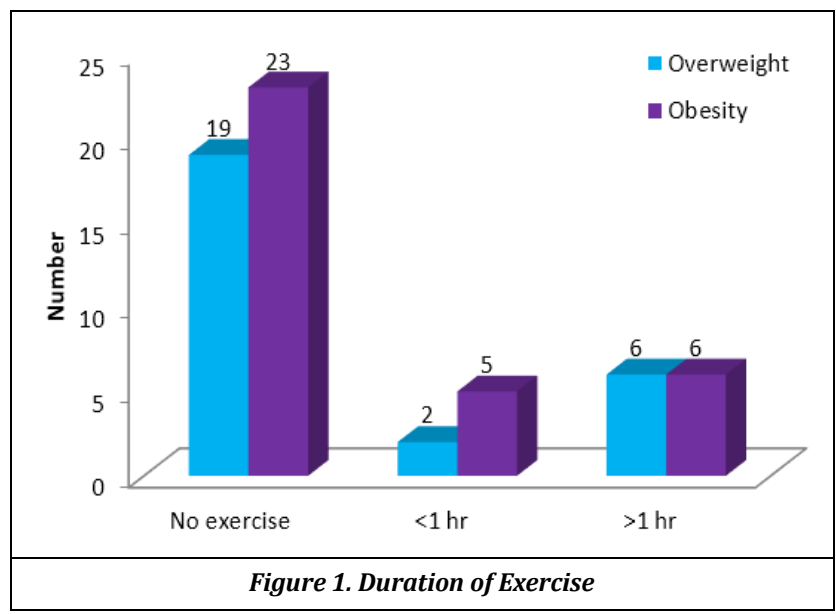

\begin{tabular}{|c|c|c|c|c|c|}
\hline \multirow{2}{*}{ Triceps } & $\begin{array}{c}\text { BMI Before } \\
\text { Lifestyle } \\
\text { Modification } \\
\text { (Ist Visit) }\end{array}$ & $\begin{array}{c}\text { BMI after } \\
\text { Lifestyle } \\
\text { Modi- } \\
\text { fication }\end{array}$ & BMI $\downarrow$ & $\begin{array}{c}\text { Percentage } \\
\downarrow \text { BMI }\end{array}$ \\
\cline { 2 - 6 } & Overweight & 29 & 18 & 11 & 61.11 \\
\hline \multirow{2}{*}{ Biceps } & Oberese & 35 & 21 & 9 & 42.8 \\
\cline { 2 - 6 } & Obese & 28 & 19 & 10 & 52.6 \\
\hline \multirow{2}{*}{ Thigh } & Overweight & 29 & 23 & 11 & 47.82 \\
\cline { 2 - 6 } & Obese & 35 & 23 & 11 & 47.82 \\
\hline \multirow{2}{*}{ Abdominal } & Overweight & 29 & 22 & 12 & 54.54 \\
\cline { 2 - 6 } & Obese & 35 & 24 & 14 & 58.33 \\
\hline \multirow{2}{*}{ Medial calf } & Overweight & 29 & 22 & 12 & 54.54 \\
\cline { 2 - 6 } & Obese & 34 & 23 & 14 & 60.86 \\
\hline
\end{tabular}

Table 1. Site of Skin Fold Thickness Most Effective to Predict Obesity

\section{Lifestyle Modification and BMI}

In overweight children $72 \%$ and in obese children $58 \%$, BMI reduced after lifestyle modification.

\section{Lifestyle Modification and Lipid Profile}

After lifestyle modification, cholesterol $\downarrow$ in 34 children out of 52 children, HDL $\uparrow$ in 8 out of 46, VLDL $\downarrow$ in 22 out of 54, LDL $\downarrow$ in 34 out of 53, TG $\downarrow$ in 35 out of 51 and FBS $\downarrow$ in 17 out of 18 children.

\section{DISCUSSION}

\section{Gender Distribution and Obesity}

The aim of the present study is to study the effect of lifestyle modification on BMI, skin fold thickness and lipid profile in obese and overweight children aged 7-11 years. 64 children were included in this study, of these 34 were boys and 30 were girls. There is no gender preponderance. The study samples belong to pre-pubertal age group. In the present study $53 \%$ of boys and $47 \%$ of girls are affected when compared to one similar study ${ }^{3}$ which shows female preponderance.

\section{Physical Exercise and Obesity}

At least 1-hour physical activity is recommended to prevent childhood obesity and lack of regular physical exercise is the most important risk factor in developing childhood obesity. In the present study, majority of children are not doing any exercise. In the present study, $18.8 \%$ of children are taking 1 - 
hour physical activity per day which is supported by one study from Risk behaviour surveillance CDC results which shows that current levels of physical activity is $19.3 \%$ (Mean). ${ }^{13}$

\section{TV Viewing Time with Obesity}

Increased screen time is an important risk factor in childhood obesity. Watching TV is the most important risk factor. In present study $46.9 \%$ TV viewed more than 2 hours when compared to Sirikulchayanonta study $74.3 \% .{ }^{14}$ Another study by Dietz WH opined that prevalence of obesity is increased by $2 \%$ for each additional hour of TV viewed. ${ }^{15}$

\section{Sleeping Hours and Obesity}

In the present study $87.5 \%$ were less than normal hour sleep when compared to Xiaoli Chen which is $92 \%$. This shows a very high correlation between inadequate sleep ${ }^{16}$ and obesity. Most of our children with obesity were having inadequate sleep. Several studies show that extra one-hour sleep will help to reduce over-weight. ${ }^{10}$

\section{Dietary Pattern and Obesity}

In the present study the percentage of children taking high fat diet is only $20 \%$, but majority of them are taking four major meals containing excess carbohydrate. So fat rich food is not a cause for obesity in the study group. Sirikulchayanonta ${ }^{14}$ in his study mentioned that children eating more than 3 meals per day are having 3.3 times risk of becoming obese.

\section{Fruits and Vegetables Intake and Obesity}

Intake of fruits and vegetables was very low in our children. In the present study, very few are taking adequate vegetables. Various studies showed that children who ate more fruits and vegetables show low risk for overweight. A study by Epstein $\mathrm{LH}^{17}$ clearly mentions the importance of fruits in preventing obesity.

\section{Lifestyle Modification and Obesity}

Lifestyle modification is the modality of treatment in childhood obesity, but that requires support of not only the child but also the whole family members. If strict lifestyle modification is carried out encouraging results will be obtained especially in overweight category. The present study shows reduction in BMI after lifestyle modification for one year, but the improvement is better for overweight child. One study by Peter Koncsos et al ${ }^{18}$ says that after 2 weeks long supervised diet and aerobic exercise program, there was a significant decrease in BMI. In the present study BMI is reduced in many children after lifestyle modification but BMI is significantly reduced in overweight boys compared to girls. This is due to increased physical activity in boys compared to girls.

\begin{tabular}{|c|c|c|}
\hline Parameters BMI Kg/ $\mathbf{m}^{\mathbf{2}}$ & Peter Koncsos et al ${ }^{\mathbf{1 9}}$ Study & Present Study \\
\hline Before lifestyle modification & 28.95 & 24.30 \\
\hline After lifestyle modification & 27.43 & 23.20 \\
\hline \multicolumn{2}{|c|}{ Table 2. Effect of Lifestyle Modification on BMI before and } \\
after Lifestyle Modification \\
\hline
\end{tabular}

\section{Skin Fold Thickness and Obesity}

Skin fold thickness, even though a cumbersome procedure can be used in assessment and follow-up of children with obesity. Triceps skin fold thickness is the most studied one. In the present study we have used 5 different sites for skin fold thickness measurement, but triceps skin fold thickness is found to be very effective in overweight children (61.11\%) when compared to other sites after lifestyle modification.

\begin{tabular}{|}
\begin{tabular}{|c|c|c|c|}
\hline \multicolumn{2}{|c|}{ Study by Rodgers DV } & \multicolumn{2}{c|}{ Present Study } \\
\cline { 3 - 4 } & Overweight & Obesity \\
\hline $\begin{array}{c}\text { Triceps skinfold thickness } \\
\text { mean change }\end{array}$ & -0.82 & -1.28 & -1.61 \\
\hline \multicolumn{2}{|c|}{ Table 3. Triceps Skin Fold Thickness Changes } \\
due to Lifestyle Modification
\end{tabular} \\
\hline
\end{tabular}

\section{Lifestyle Modification on Lipid Profile}

Present study shows that lipid profile fraction like total cholesterol and triglyceride levels show a declining trend, other parameters not showing much change after each visit. Among various studies one study by Peter Koncsos shows the following results. ${ }^{18}$

\begin{tabular}{|c|c|c|c|c|}
\hline & \multicolumn{2}{|c|}{ Peter Koncsos Study $\mathbf{1 8}$} & \multicolumn{2}{c|}{ Present Study } \\
\cline { 2 - 5 } & $\begin{array}{c}\text { Before Lifestyle } \\
\text { Modification } \\
\text { mmol/L }\end{array}$ & $\begin{array}{c}\text { After Lifestyle } \\
\text { Modification } \\
\text { mmol/L }\end{array}$ & $\begin{array}{c}\text { Before } \\
\text { Lifestyle } \\
\text { Modification } \\
\text { Ist Visit }\end{array}$ & $\begin{array}{c}\text { After } \\
\text { Lifestyle } \\
\text { Modification } \\
\text { Ind Visit }\end{array}$ \\
\hline T. Chol. & $4.35 \pm 0.91$ & $3.48 \pm 0.83$ & 183 & 169 \\
\hline HDL & $1.15 \pm 0.26$ & $1.07 \pm 0.23$ & 44 & 42 \\
\hline LDL & $2.62 \pm 0.79$ & $2.15 \pm 0.81$ & 119 & 117 \\
\hline TG & $1.62 \pm 1.50$ & $0.63 \pm 0.30$ & 128 & 120 \\
\hline \multicolumn{4}{|c|}{ Table 4. Lipid Profile Changes before and after } \\
Lifestyle Modification (n=53) \\
\hline
\end{tabular}

\section{Fasting Blood Sugar and Lifestyle Modification}

Percentage of children with fasting blood sugar $<100 \mathrm{mg} \%$ increases after lifestyle modification. This shows that incidence of diabetes mellitus can be reduced by lifestyle modification

\section{CONCLUSIONS}

Childhood obesity has no gender preponderance and in majority of children it starts before 5 years of age. Major risk factors identified in childhood obesity are lack of physical exercise, excessive TV viewing, inadequate sleep and wrong selection of food items i.e. eating food containing excess of carbohydrates, lack of adequate fruits and vegetables and large baby. Even though skin fold thickness measurement is a cumbersome procedure, triceps skin fold thickness measurement is an important tool to assess overweight and obesity, and to evaluate its course. Lifestyle modification is effective in reducing body mass index in childhood obesity. Significant reduction is seen in overweight boys compared to girls. Lifestyle modification is useful in bringing down total cholesterol, triglyceride cholesterol and elevation of HDL cholesterol. Other lipid profile fractions show variable responses. There was no significant reduction in fasting blood sugar to normal level with lifestyle modification in this study.

\section{REFERENCES}

[1] World Health Organization preventing chronic diseases. A vital investment. World global report, Geneva, WHO 2002.

[2] Overweight and obesity. www.kerala.gov.in/keralacalljan04/p26-28.pdf. 
[3] Barlow SE, Dietz WH. Obesity evaluation and treatment: expert committee recommendations. The Maternal and Child Health Bureau, Health Resources and Services Administration and the Department of Health and Human Services. Pediatrics 1998;102(3):E29.

[4] Nanda K. Gallon-lie N. Steatohepatitis in children. Pediatr Transplant 2004;8(6):613-8.

[5] Li X, Li S, Ulusoy E, et al. Childhood adiposity as a predictor of cardiac mass in adulthood: the Bongalusa Heart study. Circulation 2004;110(22):3488-92.

[6] James J, Kerr D. Prevention of childhood obesity by reducing soft drinks. Int J Obes (Lond) 2005;(29 Suppl 2):S54-S7.

[7] Davis B, Carpenter C. Proximity of fast-food restaurants to schools and adolescent obesity. Am J Public Health 2009;99(3):505-10.

[8] "Obesity study bears fruit (http://www.theage.com.au/news/national/obesitystudy-bears-fruit/2006/08/24/1156012648038.html)", Jamie Oliver, 24 August 2006.

[9] Epstein LH, Roemmich JN, Robinson JI, et al. A randomized trial of the effects reducing television viewing and computer use of on body mass index in young children. Arch Pediatr Adolesc Med 2008;162(3):239-45.

[10] Snell EK, Adam EK, Duncan GJ. Sleep and the body mass index and overweight status of children and adolescents. Child Development 2007;78(1):309-23.
[11] Horton TJ, Drougas $H$, Brachey A, et al. Fat and carbohydrate overfeeding in humans: different effect on energy storage. Am J Clin Nutr 1995;62(1):19-29.

[12] Fitness testing, Anthropometry, skin fold measurement size. Topendesports.com/.../ skinfold-sites.htm.

[13] Eaton DK, Kann L, Kinchen S, et al. Youth risk behavior surveillance - United States, 2009. MMWR Surveill Summ 2010;59(5):1-142.

[14] Sirikulchayanonta C, Ratanopas W, Temcharoen P, et al. Self-discipline and obesity in Bangkok school children. BMC Public Health 2011;11:158.

[15] Dietz WH Jr, Gortmaker SL. Do we fatten our children at the television set? Obesity and television viewing in children and adolescents. Paediatrics 1985;75(5):807-12.

[16] Ferber R. Solve your children's sleep problems. Chapter 8. 18th edn. New York: Simon \& Schuster 1985: p. 45.

[17] Epstein LH, Gordy CC, Raynor HA, et al. Increasing fruit and vegetables intake in families at risk for childhood obesity. Obesity Research 2001;9(3):171-8.

[18] Koncsos P, Seres I, Harangi M, et al. Favorable effect of short-term lifestyle intervention on human paraoxonase1 activity and adipokine levels in childhood obesity. J Am Col Nutr 2011;30(5):333-9. 